\title{
Thermal, Pasting and Gel Textural Properties of Commercial Starches from Different Botanical Sources
}

\author{
Shujing Li, Yingquan Zhang, Yimin Wei, Wei Zhang and Bo Zhang* \\ Institute of Agro-Products Processing Science \& Technology, Chinese Academy of Agricultural Sciences, Key Laboratory of Agricultural Product Processing, Ministry of \\ Agriculture, P.O. Box 5109, Beijing 100193, People's Republic of China
}

\begin{abstract}
The applications of starch in food systems are primarily governed by its gelatinization, pasting, solubility, swelling and digestibility properties. To select the appropriate variety starch for end-use suitability, thermal, pasting and ge textural properties of nine starches were determined. Commercial grade wheat starch, corn starch, potato starch, sweet potato starch, cassava starch, mung bean starch, pea starch, amylose from potato, and amylopectin from waxy corn were used in the research aim to the industry end-use. Wheat starch showed the lowest transition temperatures (the onset temperature, $T_{0}$ and the peak temperature, $\left.T_{p}\right)$. Sweet potato starch and cassava starch showed the highest transition temperatures and the lowest enthalpy changes. Mung bean starch showed the slowest transition speed. Tuber and root starches showed higher pasting temperatures, peak viscosity, final viscosity, breakdown viscosity, setback viscosity, and lower adhesiveness. Legume starches showed the highest hardness values. Person correlations and a principal component analysis showed that the transition temperatures were negatively correlated with enthalpy change $(p<0.01)$. Peak viscosity, final viscosity, breakdown viscosity and setback viscosity were positively correlated with each other, but negatively correlated with adhesiveness. The hardness was positively correlated with springiness $(r=0.830$, $p<0.01$ ), and the cohesiveness was positively correlated with enthalpy change.
\end{abstract}

Keywords: Starch; Botanical sources; Thermal; Pasting; Gel texture; Principal component analysis

\section{Introduction}

Starch is the most abundant reserve carbohydrate in plants and a valuable ingredient in the food industry because it is widely used as a thickener, a gelling agent, a bulking agent and a water retention agent [1]. The applications of starch in food systems are primarily governed by its gelatinization, pasting, solubility, swelling and digestibility properties.

The physicochemical properties of starches depend on the botanical source from which they are isolated. The major botanical and commercial sources of starches are cereals, tubers, roots, and legumes. Many comparisons of the physicochemical and functional properties of starches from different crops have been published. Starches from cultivars of wheat [2], corn [3], potato [4], sweet potato [5], cassava [6], and mung bean [7] have been shown to vary in terms of starch composition and properties. Cereal starches contain a significant quantity of phospholipids, whereas corn and rice starches generally show higher transition temperatures than wheat and potato starches, and the highest enthalpy change values are found in potato and wheat starches. The free fatty acids in rice and corn starches contribute to their higher transition temperatures [8]. The starches from cassava and potato share similarities: these produce relatively bland pastes with higher viscosity, better clarity, and lower retrogradation rates than the starches derived from cereals. Normal cassava and potato starches have a high swelling power and a dispersed volume fraction compared with starches from other tropical root and tuber crops [9]. Tuber starches have been shown to be more susceptible than legume or cereal starches to heat-moisture treatment $[10,11]$. Potato starch exhibits higher swelling power, solubility, paste clarity, and viscosity than wheat, rice, and corn starches. Potato starch shows a higher tendency toward retrogradation compared with cereal starches [8]. In general, legume starches are characterized by a high amylose content (24-65\%) and are reportedly more viscous than cereal starches $[12,13]$.

Starch gelatinization refers to the disruption of the molecular order within the starch granules when heated in the presence of water. Evidence of the loss of an organized structure includes irreversible granule swelling, loss of birefringence, and crystallinity. Gelatinization is an energy-absorbing process that can be monitored through Differential Scanning calorimetry (DSC) and has been used for the study of starches [14]. In the DSC thermogram, thermal stability of samples can be monitored by the onset temperature $\left(\mathrm{T}_{\mathrm{o}}\right)$ or peak transition temperature $\left(\mathrm{T}_{\mathrm{p}}\right)$, while the transformed proportion is reflected by the area under the endothermic peak, representing the enthalpy change $(\Delta \mathrm{H})$. The sharpness of the transition peak measured as width at half peak height $\left(\Delta \mathrm{T}^{1 / 2}\right)$, is an index of the co-operativity of the transition from native to denatured state [15]. A study of the thermal properties of starch can guide the processing and the utilization of starch and provide information about its structure.

It is generally accepted that the increased viscosity observed during the heating of starch in water occurs mainly because of the swelling of granules. Differences in breakdown are related to differences in the rigidity/fragility of the swollen granules. The viscosity parameters during pasting are cooperatively controlled by the properties of the swollen granules and the soluble materials leached from the granules [16]. The breakdown viscosity indicates the starch's propensity for disintegration. The final viscosity indicates the ability of the starch to

${ }^{*}$ Corresponding author: Bo Zhang, Institute of Agro-Products Processing Science \& Technology, And Chinese Academy of Agricultural Sciences, Key Laboratory of Agricultural Product Processing, Ministry of Agriculture, P.O. Box 5109, Beijing 100193, People 's Republic of China, Tel: 86 01062815846; Fax: 8601062895141 E-mail: zjzb1978@126.com

Received April 29, 2014; Accepted May 23, 2014; Published May 31, 2014

Citation: Li S, Zhang Y, Wei Y, Zhang W, Zhang B (2014) Thermal, Pasting and Gel Textural Properties of Commercial Starches from Different Botanical Sources. J Bioprocess Biotech 4: 161 doi: 10.4172/2155-9821.1000161

Copyright: ( $2014 \mathrm{Li} \mathrm{S}$, et al. This is an open-access article distributed under the terms of the Creative Commons Attribution License, which permits unrestricted use, distribution, and reproduction in any medium, provided the original author and source are credited. 
form a viscous paste. The setback viscosity indicates the synaeresis of starch upon the cooling of the cooked starch pastes [17].

The gelling ability of starch is important in food manufacturing. The textural properties of starch gels are crucial criteria that are used to evaluate the performance of starch in a food system.

Although lots of studies have been conducted on starch systems, few studies have compared commercial starches originating from different starch-rich crops using the same experimental methods. Usually, the cultivars of normal starches for research are certain and with high purity. The commercial starches are usually mixed with several cultivars, and their purities are different. However, starches used for industry are mostly commercial grade. Thus, the present investigation focuses on the comparison of commercial starch samples from different origins, i.e. wheat, maize corn, potato, sweet potato, cassava, mung bean, and pea, to document the differences in their thermal, pasting, and gel textural properties. These comparisons will aid the selection of the appropriate variety for end-use suitability.

\section{Materials and Methods}

\section{Materials}

Commercial grade wheat starch, corn starch, potato starch, sweet potato starch, cassava starch, mung bean starch, pea starch, amylose from potato, and amylopectin from waxy corn were acquired in a market. The total starch contents, measured by a third-party detection institution using the Chinese standard method GB/T 5009.9-2003, are specified in Table 1 .

\section{Thermal properties of starches}

The thermal characteristics of the starches were studied using a differential scanning calorimeter (DSC, Q-200, TA Instruments, USA). The starch was mixed with water in a vial to yield a $50 \%$ moisture paste. The vial was then capped and stored at $4^{\circ} \mathrm{C}$ overnight. After allowing the vial to reach room temperature, the moisture-equilibrated starch was conditioned in hermetic aluminum TA pans, weighed (approximately $10 \mathrm{mg}$ ) using a precision balance $( \pm 0.01 \mathrm{mg}$, Analytical Plus, Mettler Toledo) and heated at a rate of $10^{\circ} \mathrm{C} \mathrm{min}-1$ from $20^{\circ} \mathrm{C}$ to $120^{\circ} \mathrm{C}$ in an inert atmosphere $\left(50 \mathrm{~mL} \mathrm{~min}^{-1}\right.$ of dry $\left.\mathrm{N}_{2}\right)$. The reference was a void aluminum TA pan. The onset temperature $(\mathrm{T})$, the peak temperature $\left(\mathrm{T}_{\mathrm{p}}\right)$, the enthalpy change $(\Delta \mathrm{H})$ and the width at half-peak height $\left(\Delta \mathrm{T}_{1 / 2}\right)$ were computed from the curves using the Universal Analysis Program (Version 1.9 D; TA Instruments). The enthalpies were calculated on a starch dry-weight basis.

\section{Pasting properties of starches}

According to AACC 76-21 STD2 [18], the pasting properties of the starches were evaluated using the Micro Visco-Amylo-Graph (Brabender, Germany). The viscosity profiles of the starches were recorded using starch suspensions $(9.21 \%$, w/w; $100 \mathrm{~g}$ total weight). The heating and cooling cycle program to which the samples were subjected was the following: heating from $30^{\circ} \mathrm{C}$ to $95^{\circ} \mathrm{C}$ at a rate of $6^{\circ} \mathrm{C} \mathrm{min}^{-1}$, holding $95^{\circ} \mathrm{C}$ for $5 \mathrm{~min}$, cooling from $95^{\circ} \mathrm{C}$ to $50^{\circ} \mathrm{C}$ at a rate of $6^{\circ} \mathrm{C}$ $\mathrm{min}^{-1}$, and holding at $50^{\circ} \mathrm{C}$ for $2 \mathrm{~min}$. The parameters recorded were the pasting temperature $\left(\mathrm{P}_{\mathrm{Temp}}\right)$, peak viscosity $(\mathrm{PV})$, final viscosity
(FV), breakdown viscosity (BV), and setback viscosity (SV). All of the measurements were replicated twice.

\section{Textural properties of starch gels}

A starch emulsion $(9.21 \%, \mathrm{w} / \mathrm{w})$ was heated from $30^{\circ} \mathrm{C}$ to $95^{\circ} \mathrm{C}$ at a rate of $6^{\circ} \mathrm{C} \mathrm{min}{ }^{-1}$, maintained at $95^{\circ} \mathrm{C}$ for $20 \mathrm{~min}$ in the Micro ViscoAmylo-Graph, poured into small beakers and stored at $4^{\circ} \mathrm{C}$ to cause gelation. The textural properties of the starch gels were measured as described by Sandhu and Singh [17]. The gels' textural properties were evaluated through a texture profile analysis (TPA) using the TA-XT2i texture analyzer (Stable MicroSystems, Surrey, England). The gel was compressed at a rate of $0.5 \mathrm{~mm} \mathrm{~s}^{-1}$ to a distance of $10 \mathrm{~mm}$ with a cylindrical plunger (diameter $=10 \mathrm{~mm}$ ). The compression was repeated twice to generate a force-time curve from which the hardness (the height of the first peak) and springiness (the ratio between the recovered height after the first compression and the original gel height) were determined. The negative area of the curve during the retraction of the probe was termed the adhesiveness. The cohesiveness was calculated as the ratio of the area under the second peak to the area under the first peak. Five repeated measurements were performed for each sample and their average was used for the analysis.

\section{Statistical analysis}

One-way Analysis of Variance (ANOVA), Pearson correlation coefficients $(r)$ for the relationships between all of the properties, and a Principal Component Analysis (PCA) were performed using the PASW Statistics 18.0 software. The comparisons between treatments were evaluated using Duncan's test. The significance level was set to $95 \%$ for all of the data analyses.

\section{Results}

\section{Thermal properties of starches}

The DSC curves of the starches are shown in Figure 1. The transition

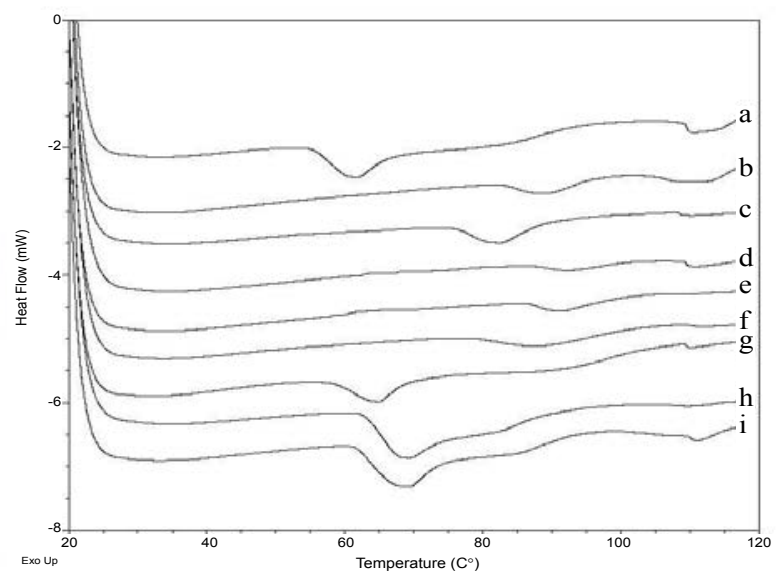

Figure 1: DSC endotherms of the gelatinization of starches: (a) wheat starch (b) corn starch; (c) potato starch; (d) sweet potato starch; (e) cassava starch; (f) mung bean starch; (g) pea starch; (h) amylose; and (i) amylopectin. The moisture content was $50 \%$, and the heating rate was $10^{\circ} \mathrm{C} \mathrm{min}^{-1}$.

\begin{tabular}{|c|c|c|c|c|c|c|c|c|c|}
\hline Variety & Wheat starch & Corn starch & Potato starch & $\begin{array}{c}\text { Sweet potato } \\
\text { starch }\end{array}$ & $\begin{array}{l}\text { Cassava } \\
\text { starch }\end{array}$ & $\begin{array}{l}\text { Mung bean } \\
\text { starch }\end{array}$ & Pea starch & Amylose & Amylopectin \\
\hline Starch content(\%. d.b) & $94.52 d \pm 0.00$ & $99.51 \mathrm{a} \pm 0.00$ & $98.44 a \pm 0.74$ & $99.23 a \pm 0.57$ & $93.98 d \pm 0.02$ & $97.37 b \pm 0.42$ & $95.75 c \pm 0.55$ & $98.66 a \pm 0.63$ & $92.90 \mathrm{e} \pm 0.31$ \\
\hline
\end{tabular}

Table 1: Total starch content of various starches. 
Citation: Li S, Zhang Y, Wei Y, Zhang W, Zhang B (2014) Thermal, Pasting and Gel Textural Properties of Commercial Starches from Different Botanical Sources. J Bioprocess Biotech 4: 161 doi: 10.4172/2155-9821.1000161

Page 3 of 6

temperatures (onset, $\mathrm{T}_{\mathrm{o}}$; peak, $\mathrm{T}_{\mathrm{p}}$ ), the enthalpy change $(\Delta \mathrm{H})$ and the width at half-peak height $\left(\Delta \mathrm{T}_{1 / 2}\right)$ of the gelatinization process are shown in Table 2. A significant difference was observed among the varieties of starches. Wheat starch had the lowest gelatinization temperatures. Sweet potato starch had the highest gelatinization temperatures, indicating that more energy is required to initiate the gelatinization of this starch. The $\Delta \mathrm{H}$ for the various starches ranged from 0.49 to $5.29 \mathrm{~J} / \mathrm{g}$. The $\Delta \mathrm{T}_{1 / 2}$ of mung bean starch $\left(12.14^{\circ} \mathrm{C}\right)$ was considerably higher than that of the other starches. The corn, sweet potato, and cassava starches showed the highest transition temperatures and the lowest $\Delta \mathrm{H}$.

\section{Pasting properties of starches}

The pasting properties of the various starches are summarized in Figure 2 and Table 3. A significant difference in the pasting properties was observed among the different starches was observed. The corn and amylopectin starches have a substantial higher pasting temperature than the other starches. The peak viscosities (PV) of the various starches ranged from 405.50 to $2148.00 \mathrm{~m} \mathrm{~Pa} \bullet \mathrm{s}$, and the root and tuber starches exhibited had the highest PV values: $2148.00 \mathrm{~m}$ Pa•s for potato, 1239.00 $\mathrm{m}$ Pa $\bullet$ for cassava, $1006.00 \mathrm{~m}$ Pa•s for amylose, and $983.00 \mathrm{~m}$ Pa $\bullet$ for sweet potato. The wheat and pea starches presented a low peak viscosity. The final viscosity (FV) of the different starches ranged from 462.00 to $1647.50 \mathrm{~m}$ Pa•s, with the lowest values observed in wheat starch and the highest found in potato starch. Pea starch exhibited the lowest breakdown viscosity (BV) whereas potato starch presented the highest value. The setback viscosity (SV) for the various starches differed significantly. Pea starch exhibited the lowest SV $(229.00 \mathrm{~m}$ Pa•s), whereas potato starch had the highest SV (949.50 m Pa•s). The $\mathrm{PV}, \mathrm{FV}, \mathrm{BV}$, and SV of amylose were higher than those of amylopectin. The pasting properties of the tuber and root starches were significantly higher than those of the cereal and legume starches.

\section{Gel texture properties of starch gels}

The textural properties of starch gels, which were determined

\begin{tabular}{|c|c|c|c|c|}
\hline Variety & $\mathrm{T}_{0}\left({ }^{\circ} \mathrm{C}\right)$ & $\mathrm{T}_{\mathrm{p}}\left({ }^{\circ} \mathrm{C}\right)$ & $\Delta \mathbf{H}(\mathbf{J} / \mathbf{g})$ & $\Delta \mathbf{T}_{1 / 2}\left({ }^{\circ} \mathrm{C}\right)$ \\
\hline Wheat starch & $56.00 \mathrm{~g} \pm 0.33$ & $61.25 f \pm 0.37$ & $3.51 b c \pm 0.07$ & $6.56 b \pm 0.30$ \\
\hline Corn starch & $83.62 b \pm 0.57$ & $89.12 b \pm 0.02$ & $1.08 \mathrm{fg} \pm 0.34$ & $7.20 b \pm 0.40$ \\
\hline Potato starch & $77.34 d \pm 1.46$ & $83.16 c \pm 0.82$ & $2.32 \mathrm{de} \pm 0.80$ & $6.90 b \pm 0.93$ \\
\hline Sweet potato starch & $87.81 a \pm 0.55$ & $92.76 a \pm 0.19$ & $0.49 g \pm 0.30$ & $6.98 b \pm 1.10$ \\
\hline Cassava starch & $85.78 a b \pm 1.23$ & $90.62 b \pm 0.80$ & $1.74 \mathrm{ef} \pm 0.42$ & $7.20 b \pm 0.01$ \\
\hline Mung bean starch & $80.00 c \pm 1.78$ & $89.40 \mathrm{~b} \pm 1.82$ & $2.15 \mathrm{def} \pm 0.15$ & $12.14 a \pm 0.65$ \\
\hline Pea starch & $58.39 f \pm 0.75$ & $64.60 \mathrm{e} \pm 0.33$ & $3.09 \mathrm{~cd} \pm 0.93$ & $6.50 b \pm 0.78$ \\
\hline Amylose & $62.71 \mathrm{e} \pm 0.83$ & $67.93 d \pm 0.61$ & $4.36 a b \pm 0.46$ & $7.42 b \pm 0.19$ \\
\hline Amylopectin & $62.00 \mathrm{e} \pm 0.05$ & $68.13 d \pm 0.03$ & $5.29 a \pm 0.16$ & $8.04 b \pm 0.15$ \\
\hline
\end{tabular}

Table 2: Gelatinization properties of starches.

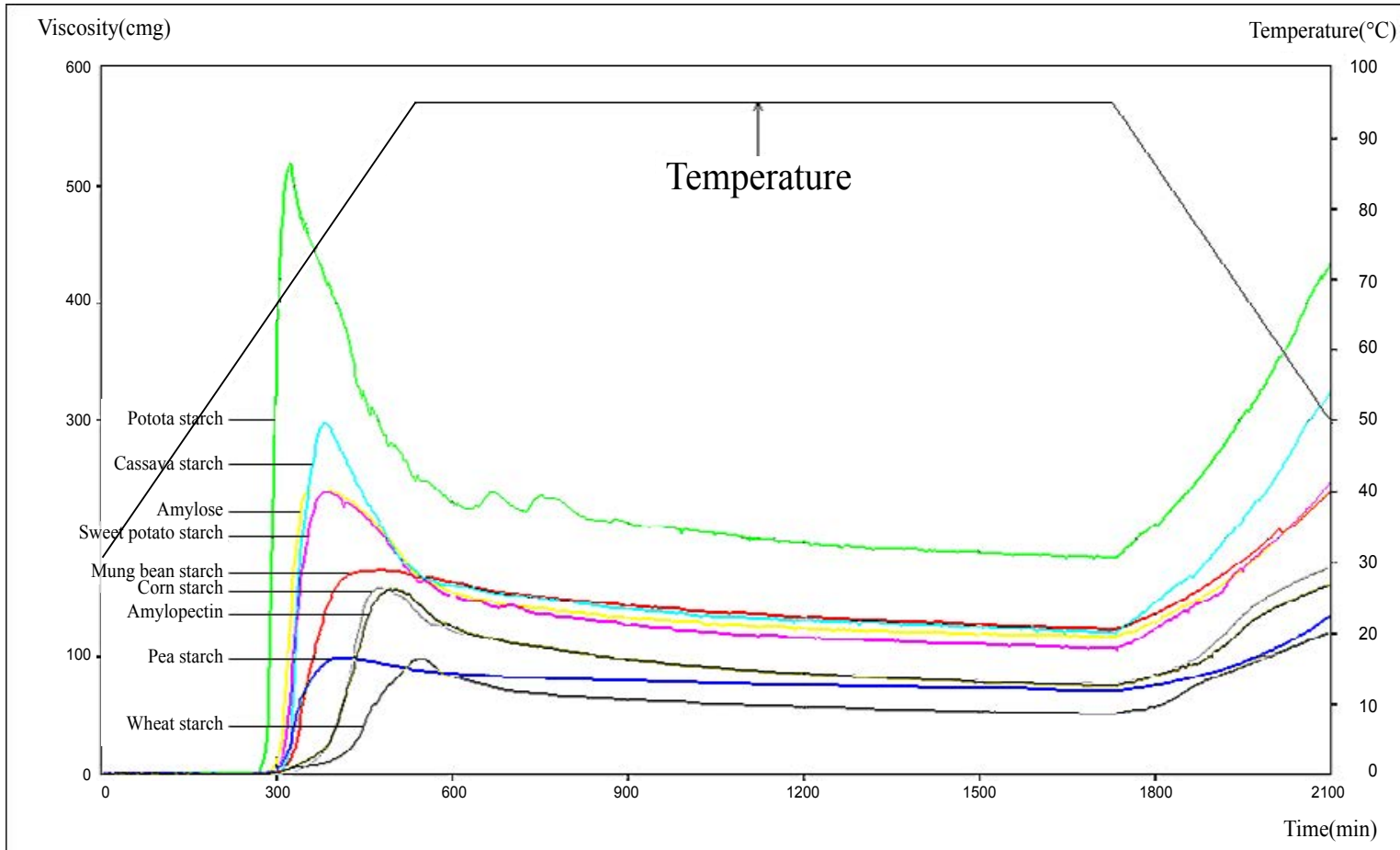

Figure 2: Pasting profiles of the various starches. 
Citation: Li S, Zhang Y, Wei Y, Zhang W, Zhang B (2014) Thermal, Pasting and Gel Textural Properties of Commercial Starches from Different Botanical Sources. J Bioprocess Biotech 4: 161 doi: 10.4172/2155-9821.1000161

Page 4 of 6

using a texture analyzer, are shown in Table 4 . As shown, the textural parameters of starches varied significantly. The legume starches showed the highest hardness (701.94 $\mathrm{g}$ for pea starch, and $587.31 \mathrm{~g}$ for mung bean starch), whereas the cassava starch gel showed the lowest hardness $(51.37 \mathrm{~g})$. The cohesiveness of the starches varied from 0.34 to 0.49 , and wheat starch, cassava starch and amylose exhibited slightly higher cohesiveness than the other starches. The springiness of the starches varied from 0.73 to 1.00 , with mung bean starch having the highest springiness. The adhesiveness of cassava starch and amylose were not detected, whereas that of the other starches varied from -28.72 to $-363.91 \mathrm{~g} \bullet \mathrm{s}$, with pea starch exhibited the highest value, and tuber and root starches presenting the lowest values.

\section{Pearson correlations among the various properties of the starches}

Several significant correlations were observed between the gelatinization, and the pasting and the gel texture properties of the starches (Table 5). Positive interrelationships between the gelatinization parameters were also observed. The $\mathrm{T}_{\mathrm{o}}$ was correlated with the $\mathrm{T}_{\mathrm{p}}$ and $\Delta \mathrm{H}(\mathrm{r}=0.994$ and -0.845 , respectively, $\mathrm{p}<0.01$ ), and the $\mathrm{T}_{\mathrm{p}}$ was negatively correlated with the $\Delta \mathrm{H}(\mathrm{r}=-0.832, \mathrm{p}<0.01)$. The adhesiveness was negatively correlated with the $\mathrm{PV}, \mathrm{BV}$, and $\mathrm{SV}(\mathrm{P}<0.05)$, and the hardness was positively correlated with the springiness $(\mathrm{r}=0.830, \mathrm{p}<0.01)$.

\section{Principal component analysis of the various properties of the starches}

A principal component analysis (PCA) was conducted on four of

the tested attributes. The results of the PCA (Figure 3) indicated that $35.64 \%$ of the variation in the data can be explained by PC1, $23.54 \%$ can be explained by PC2, $18.85 \%$ can be explained by PC3, and $9.96 \%$ can be explained by PC4. The variables that are found close to each other in pairs or groups indicate a positive correlation. The variables describing the pasting properties, specifically $\mathrm{PV}, \mathrm{FV}, \mathrm{SV}$, and $\mathrm{BV}$, were correlated with each other (Figure 3A). The loading plot shows that the pasting properties are correlated with the total starch content. The $\mathrm{T}$ is correlated with the $\mathrm{T}_{\mathrm{p}}$. The hardness is correlated with the springiness (Figure 3B).

The potato starch and cassava starch presented high positive scores in $\mathrm{PC} 1$ and were located near the $\mathrm{PC} 1$ axis (Figure $3 \mathrm{a}$ ). The sweet potato starch and mung bean starches had positive scores in the PC2 and were located near the PC2 axis. The potato, pea, and mung bean starches had positive scores in PC3 (Figure 3b).

The comparison of the score and loading plots (Figure $3 \mathrm{~A}$ and 3a) revealed that the potato starch and cassava starch showed high values of PV, FV, BV, and SV. The sweet potato starch and mung bean starch showed high values of $\mathrm{T}_{0}$ and $\mathrm{T}_{\mathrm{p}}$. The legume starches (mung bean starch and pea starch) and potato starch showed high values of hardness and springiness.

\section{Discussion}

The value of $\mathrm{T}_{\mathrm{o}}$ shows the internal structure of the granule during its disintegrationes, which results in the release of polysaccharide into the surrounding medium [19]. The heat capacity plays a major role in this process because it directly reflects the molecular structure [20].

\begin{tabular}{|c|c|c|c|c|}
\hline Variety & $\mathbf{P}_{\text {Temp }}\left({ }^{\circ} \mathbf{C}\right)$ & $\mathbf{P V}(\mathbf{m P a} \cdot \mathbf{s})$ & $\mathbf{F V}(\mathbf{m P a} \cdot \mathbf{s})$ & $\mathbf{B V}(\mathbf{m P a} \cdot \mathbf{s})$ \\
\hline Wheat starch & $66.45 \mathrm{~d} \pm 0.07$ & $405.50 \mathrm{~g} \pm 7.78$ & $462.00 \mathrm{~h} \pm 18.38$ & $198.50 \mathrm{~g} \pm 2.12$ \\
\hline Corn starch & $70.85 \mathrm{a} \pm 0.07$ & $660.00 \mathrm{f} \pm 4.24$ & $683.00 \mathrm{f} \pm 4.24$ & $342.00 \mathrm{e} \pm 4.24$ \\
\hline Potato starch & $63.80 \mathrm{f} \pm 0.57$ & $2148.00 \mathrm{a} \pm 8.49$ & $1647.50 \mathrm{a} \pm 7.78$ & $1385.50 \mathrm{a} \pm 10.61$ \\
\hline Sweet potato starch & $66.90 \mathrm{~cd} \pm 0.28$ & $983.00 \mathrm{~d} \pm 14.14$ & $913.50 \mathrm{e} \pm 14.85$ & $547.00 \mathrm{c} \pm 4.24$ \\
\hline Cassava starch & $68.45 \mathrm{~b} \pm 0.07$ & $1239.00 \mathrm{~b} \pm 8.49$ & $1165.50 \mathrm{~b} \pm 2.12$ & $732.50 \mathrm{~b} \pm 3.54$ \\
\hline Mung bean starch & $67.55 \mathrm{bc} \pm 0.21$ & $716.50 \mathrm{e} \pm 2.12$ & $1012.00 \mathrm{c} \pm 31.11$ & $217.50 \mathrm{f} \pm 16.26$ \\
\hline Pea starch & $67.40 \mathrm{c} \pm 0.00$ & $411.00 \mathrm{~g} \pm 0.00$ & $687.50 \mathrm{f} \pm 14.85$ & $117.50 \mathrm{~h} \pm 2.12$ \\
\hline Amylose & $65.05 \mathrm{e} \pm 0.07$ & $1006.00 \mathrm{c} \pm 5.66$ & $962.50 \mathrm{~d} \pm 26.16$ & $508.00 \mathrm{~d} \pm 9.90$ \\
\hline Amylopectin & $70.20 \mathrm{a} \pm 0.99$ & $661.50 \mathrm{f} \pm 10.61$ & $629.50 \mathrm{~g} \pm 6.36$ & $347.50 \mathrm{e} \pm 3.54$ \\
\hline
\end{tabular}

$\mathrm{P}_{\text {Temp }}$, pasting temperature; PV, peak viscosity; FV, final viscosity; BV, breakdown viscosity; SV, setback viscosity

Table 3: Pasting properties of the different starches.

\begin{tabular}{|c|c|c|c|c|}
\hline Variety & Hardness(g) & Cohesiveness & Springiness & adhesiveness $(\mathrm{g} \cdot \mathbf{s})$ \\
\hline Wheat starch & $95.30 \mathrm{e} \pm 4.50$ & $0.46 a \pm 0.01$ & $0.86 c d \pm 0.02$ & $-304.97 a b \pm 29.89$ \\
\hline Corn starch & $152.88 \mathrm{~cd} \pm 17.00$ & $0.35 b \pm 0.04$ & $0.88 e \pm 0.03$ & $-212.90 b c \pm 88.50$ \\
\hline Potato starch & $546.84 b \pm 88.28$ & $0.38 b \pm 0.05$ & $0.99 a b \pm 0.02$ & $-28.72 d \pm 19.64$ \\
\hline Sweet potato starch & $103.35 \mathrm{de} \pm 9.51$ & $0.34 b \pm 0.03$ & $0.73 f \pm 0.06$ & $-45.30 d \pm 15.89$ \\
\hline Cassava starch & $51.37 e \pm 5.71$ & $0.49 a \pm 0.03$ & 0.79 ef \pm 0.03 & $n d^{a}$ \\
\hline Mung bean starch & $587.31 b \pm 55.25$ & $0.36 b \pm 0.01$ & $1.00 \mathrm{a} \pm 0.05$ & $-230.79 a b c \pm 187.18$ \\
\hline Pea starch & $701.94 a \pm 33.10$ & $0.38 b \pm 0.03$ & $0.92 b c \pm 0.12$ & $-363.91 a \pm 182.99$ \\
\hline Amylose & $61.94 e \pm 9.30$ & $0.49 a \pm 0.02$ & 0.79 ef \pm 0.02 & nd \\
\hline Amylopectin & $168.28 \mathrm{c} \pm 34.78$ & $0.38 b \pm 0.09$ & $0.81 \mathrm{de} \pm 0.03$ & $-93.52 c d \pm 43.86$ \\
\hline
\end{tabular}

and stands for not detected

Table 4: Textural properties of starch gels. 
Citation: Li S, Zhang Y, Wei Y, Zhang W, Zhang B (2014) Thermal, Pasting and Gel Textural Properties of Commercial Starches from Different Botanical Sources. J Bioprocess Biotech 4: 161 doi: 10.4172/2155-9821.1000161

Page 5 of 6

\begin{tabular}{|c|c|c|c|c|c|c|c|c|c|c|c|c|c|}
\hline & $\begin{array}{l}\text { Starch } \\
\text { content }\end{array}$ & $T_{0}$ & $T_{p}$ & $\Delta \mathbf{H}$ & $\Delta \mathbf{T}_{1 / 2}$ & $\mathbf{P}_{\text {Temp }}$ & PV & FV & BV & sv & hardness & cohesiveness & springiness \\
\hline $\mathrm{T}_{\mathrm{o}}$ & 0.466 & & & & & & & & & & & & \\
\hline$T_{p}$ & 0.464 & $0.994^{* *}$ & & & & & & & & & & & \\
\hline$\Delta \mathrm{H}$ & -0.564 & $-0.845^{\star *}$ & $-0.832^{* *}$ & & & & & & & & & & \\
\hline$\Delta \mathrm{T}_{1 / 2}$ & 0.044 & 0.232 & 0.329 & -0.011 & & & & & & & & & \\
\hline $\mathrm{P}_{\text {Temp }}$ & -0.309 & 0.165 & 0.170 & -0.058 & 0.139 & & & & & & & & \\
\hline PV & 0.311 & 0.443 & 0.421 & -0.228 & -0.117 & -0.565 & & & & & & & \\
\hline FV & 0.340 & 0.506 & 0.509 & -0.299 & 0.104 & -0.571 & $0.948^{* *}$ & & & & & & \\
\hline BV & 0.261 & 0.409 & 0.374 & -0.215 & -0.238 & -0.532 & $0.988^{* *}$ & $0.894^{* *}$ & & & & & \\
\hline SV & 0.231 & 0.589 & 0.563 & -0.349 & -0.067 & -0.443 & $0.959^{* *}$ & $0.936^{* *}$ & $0.945^{\star *}$ & & & & \\
\hline Hardness & 0.095 & -0.120 & -0.047 & -0.029 & 0.327 & -0.242 & 0.093 & 0.281 & 0.021 & -0.020 & & & \\
\hline cohesiveness & -0.387 & -0.339 & -0.380 & 0.400 & -0.256 & -0.285 & 0.054 & 0.019 & 0.072 & 0.149 & -0.468 & & \\
\hline springiness & 0.126 & -0.069 & 0.007 & -0.022 & 0.437 & -0.216 & 0.179 & 0.319 & 0.119 & 0.086 & $0.830^{\star *}$ & -0.321 & \\
\hline adhesiveness & -0.166 & -0.453 & -0.408 & 0.051 & -0.084 & 0.244 & $-0.709^{*}$ & -0.620 & $-0.702^{*}$ & $-0.749^{\star}$ & 0.479 & -0.276 & 0.458 \\
\hline
\end{tabular}

${ }^{*}$ Correlation is significant $(P<0.05)$

${ }^{* *}$ Correlation is significant $(p<0.01)$

Table 5: Pearson correlation coefficients between the various properties of the starches.
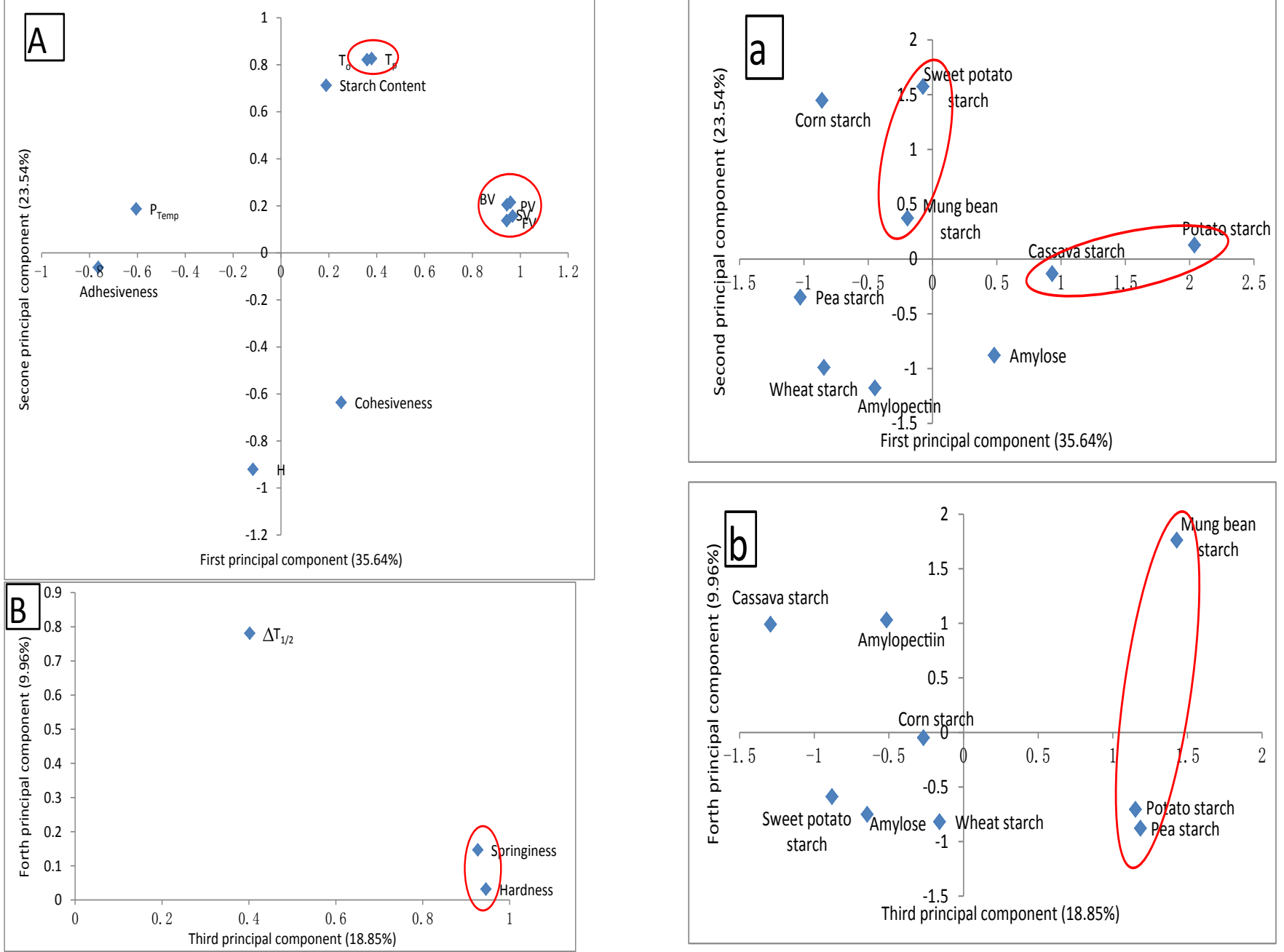

Figure 3: (A) Loading plot and (a) score plot of the principal components 1 and 2. (B) Loading plot and (b) score plot of the principal components 3 and 4, describing the variation in the physicochemical properties of the nine starch samples. 
Citation: Li S, Zhang Y, Wei Y, Zhang W, Zhang B (2014) Thermal, Pasting and Gel Textural Properties of Commercial Starches from Different Botanical Sources. J Bioprocess Biotech 4: 161 doi: 10.4172/2155-9821.1000161

Higher enthalpies and temperatures indicate a higher degree of granule crystallinity [21]. According to our results, $\mathrm{T}_{\mathrm{o}}$ and $\mathrm{T}_{\mathrm{p}}$ are negatively correlated with the $\Delta H(n=9, r=-0.845$ and $-0.832, p<0.01)$.

Singh et al. [13] studied the thermal and pasting properties of 13 different black gram cultivars. The $\mathrm{T}_{\mathrm{o}}$ varied from 66.1 to $71.3^{\circ} \mathrm{C}$ (the moisture content was $70 \%$ ); the PV varied from 422 to $514 \mathrm{RVU}$; and the BV varied from 134 to $212 \mathrm{RVU}$. The PV, and BV were negatively correlated with the $T_{o}(n=13, r=-0.794$ and $-0.835, p<0.01)$. The $P_{\text {Temp }}$ was positively correlated with the $\mathrm{T}_{\mathrm{o}}(\mathrm{n}=13, \mathrm{r}=0.961, \mathrm{p}<0.01)$. During the pasting process, the starch granules first swell; and this swelling is followed by the melting of crystals and then the paste becoming viscous.

The variations in $\Delta \mathrm{H}$ may represent differences in the bonding forces between the double helices that form the amylopectin crystallites, which alter the alignment of hydrogen bonds within the starch molecules [17]. According to previous results, the PV, FV, BV, and SV of starch emulsions are slightly negatively correlated with the $\Delta \mathrm{H}(\mathrm{n}=9 ; \mathrm{r}=-0.743,-0.623,-0.733$, and -0.611 , respectively; $\mathrm{P}<0.05)$, and the $\mathrm{P}_{\text {Temp }}$ and the hardness of the starch gel are positively correlated with $\Delta \mathrm{H}(\mathrm{r}=0.620, \mathrm{p}<0.05 ; \mathrm{r}=0.44, \mathrm{p}<0.01)$ [22]. Bao et al. [23] observed a significant positive correlation between $\Delta H$ and cohesiveness $(n=127$, $\mathrm{r}=0.234, \mathrm{P}<0.05)$ in rice starch.

\section{Conclusion}

In the present study, variations in the thermal, pasting and gel texture properties were observed between different varieties of starches. Wheat starch showed the lowest transition temperatures (the onset temperature, $\mathrm{T}_{\mathrm{o}}$ and the peak temperature, $\mathrm{T}_{\mathrm{p}}$ ). The root starches (sweet potato starch, cassava starch) showed the highest transition temperatures and the lowest enthalpy change values. Mung bean starch showed the slowest transition speed. The tuber and root starches showed higher viscosities (peak viscosity, final viscosity, breakdown viscosity and setback viscosity) and lower adhesiveness. The legume starches showed the highest hardness values. The properties of amylose and amylopectin largely depended on their source.

The peak viscosity, final viscosity, breakdown viscosity and setback viscosity were positively correlated with each other and were positively correlated with the starch content. The onset temperature was negatively correlated with the enthalpy change. The pasting temperature was positively correlated with onset temperature and the final viscosity, setback viscosity, and pasting temperature were negatively correlated with the enthalpy change.

\section{Acknowledgment}

The authors acknowledge the Special Fund for Agro-scientific Research in the Public Interest (Grant No. 201303071) and the National Natural Science Foundation of China (31101377)

\section{References}

1. Sandhu KS, Singh N, Kaur M (2004) Characteristics of the different corn types and their grain fractions: physicochemical, thermal, morphological, and rheological properties of starches. J Food Eng 64: 119-127.

2. Wootton M, Mahdar D (1993) Properties of starches from Australian wheats Part 2: Some Physico-chemical Properties. Starch 45: 295-299.

3. Yun SH, Matheson NK (1993) Structures of the amylopectins of waxy, normal, amylose-extender, and wx:ae genotypes and of the phytoglycogen of maize. Carbohyd Res 243: 307-321.

4. Alvani K, Qi X, Tester RF, Snape CE (2011) Physico-chemical properties of potato starches. Food Chem 125: 958-965.

5. Collado LS (1997) Physical properties and utilization of sweet potato starch and flour. PhD thesis. University of Hong Kong.
6. Asaoka M, Blanshard JMV, Rickard JE (1991) Effects on the Physico $\square$ chemical Properties of Starch from Four Cultivars of Cassava. Starch 43: 455-459.

7. Hoover R, Li YX, Hynes G, Senanayake N (1997) Physicochemical characterization of mung bean starch. Food Hydrocolloid 11: 401-408.

8. Singh N, Singh J, Kaur L, Sodhi NS, Gill BS (2003) Morphological, thermal and rheological properties of starches from different botanical sources. Food Chem 81: 219-231.

9. Sánchez T, Dufour D, Moreno IX, Ceballos H (2010) Comparison of pasting and gel stabilities of waxy and normal starches from potato, maize, and rice with those of a novel waxy cassava starch under thermal, chemical, and mechanical stress. J Agr Food Chem 58:5093-5099.

10. Hoover R, Vasanthan $T$ (1994) Effect of heat-moisture treatment on the structure and physicochemical properties of cereal, legume, and tuber starches. Carbohyd Res 25: 33-53.

11. Jacobs H, Delcour JA (1998) Hydrothermal modifications of granular starch with retention of the granular structure: A review. J Agr Food Chem 46: 28952905.

12. Ratnayake WS, Hoover R, Warkentin T (2002) Pea starch: Composition, structure and properties: A review. Starch 54: 217-234.

13. Singh N, Kaur M, Sandhu KS, Guraya HS (2004) Physicochemical, thermal morphological and pasting properties of starches from some Indian black gram (Phaseolus mungo L.) cultivars. Starch 56: 535-544.

14. Freitas RA, Paula RC, FeitosaJPA, Rocha S, Sierakowski MR (2004) Amylose contents, rheological properties and gelatinization kinetics of yam (Dioscorea alata) and cassava (Manihot utilissima) starches. Carbohyd Polym 55: 3-8.

15. Li-Chan ECY, Ma CY (2002) Thermal analysis of flaxseed (Linum usitatissimum) proteins by differential scanning calorimetry. Food Chem 77: 495-502.

16. Doublier JL, Llamas G, Le Meur M (1987) A rheological investigation of cereal starch pastes and gels. Effect of pasting procedures. Carbohyd Polym 7: 251275.

17. Sandhu KS, Singh N (2007) Some properties of corn starches II: Physicochemical, gelatinization, retrogradation, pasting and gel textural properties. Food Chem 10: 1499-1507.

18. AACCI (1995) General pasting method for wheat or rye flour using the rapid visco analyser. 11th Edtn, AACC International Approved Methods

19. Singh N, Kaur L, Sandhu KS, Kaur J, Nishinari K (2006) Relationships between physicochemical, morphological, thermal, rheological properties of rice starches. Food Hydrocolloid 20: 532-542.

20. Louaer W,Meniai AH, Grolier JPE (2008) Thermal analysis of the influence of water content on glass transitions. J Therm Anal Calorim 93: 605-610.

21. Svegmark K, Helmersson K, Nilsson G, Nilsson PO, Andersson R, et al. (2002) Comparison of potato amylopectin starches and potato starches-influence of year and variety. Carbohyd Polym 47: 331-340.

22. Singh SK, Johnson LA, White PJ, JaneJL, Pollak LM (2001) Thermal properties and paste and gel behaviors of starches recovered from accessions used in the germplasm enhancement of maize project. Cereal Chem 78: 315-321.

23. Bao J, Sun M,Zhu L, Corke HJ (2004) Analysis of quantitative trait loci for some starch properties of rice (Oryza sativa L.): thermal properties, gel texture and swelling volume. Cereal Sci 39: 379-385. 